\title{
Adesão ao tratamento antirretroviral e supressão viral entre pacientes do Hospital de Clínicas da Unicamp: buscando a meta UNAIDS 90-90-90
}

\author{
Adherence to antiretroviral treatment and viral suppression among patients at Unicamp's Hospital
}

de Clínicas: seeking the UNAIDS goal 90-90-90

Adherencia al tratamiento antirretroviral y supresión viral entre los pacientes del Hospital de

Clínicas de la Unicamp: en busca del objetivo UNAIDS 90-90-90

Recebido: 05/10/2021 | Revisado: 12/10/2021 | Aceito: 14/10/2021 | Publicado: 17/10/2021

\author{
Márcio Cristiano de Melo \\ ORCID: https://orcid.org/0000-0001-9840-0309 \\ Universidade Estadual de Campinas, Brasil \\ E-mail: enf.marciomelo@gmail.com \\ Flávio Eugenio Polillo Filho \\ ORCID: https://orcid.org/0000-0002-3093-9655 \\ Universidade Estadual de Campinas, Brasil \\ E-mail: flavio.polillo@gmail.com \\ Flávia Fernanda Moreno \\ ORCID: https://orcid.org/0000-0001-5137-3841 \\ Universidade Estadual de Campinas, Brasil \\ E-mail: flaviiafm@hotmail.com \\ Carolina Neves Bühl \\ ORCID: https://orcid.org/0000-0002-6473-7867 \\ Universidade Estadual de Campinas, Brasil \\ E-mail: carolbuhl@gmail.com \\ Maria Rita Donalisio \\ ORCID: https://orcid.org/0000-0003-4457-9897 \\ Universidade Estadual de Campinas, Brasil \\ E-mail: rita.donalisio@gmail.com
}

\begin{abstract}
Resumo
Objetivo: verificar a adesão ao tratamento antirretroviral e a supressão viral, segundo variáveis demográficas, clínicas e laboratoriais em pacientes atendidos no ambulatório de HIV/AIS do Hospital de Clínicas da Unicamp em 2016. Método: estudo transversal sobre o perfil demográfico, epidemiológico e clínico dos pacientes atendidos no Ambulatório de Infectologia no Hospital Dia da Universidade Estadual de Campinas para avaliar a adesão ao tratamento antirretroviral e eventuais eventos adversos registrados no ano de 2016. Resultados: dos 339 prontuários amostrados de Pessoas Vivendo com HIV e aids (PVHA), 278 (82,0\%) com uso regular de antirretrovirais e 293 $(86,4 \%)$ com carga viral indetectável (<40 cópias/mL). No modelo logístico múltiplo a idade, intercorrências clínicas e efeitos colaterais de medicamentos foram associados à menor adesão à tratamento antirretroviral. A supressão viral foi maior entre os homens, com mais idade e menor tempo de diagnóstico; e menos frequente nos pacientes com intercorrências clínicas e efeitos adversos da medicação. Conclusão: uma maior integração entre serviços de saúde pode facilitar a aderência de PVHA sem seguimento clínico. O manejo clínico de complicações e eventos adversos de medicamentos são relevantes para a adesão ao tratamento e à supressão viral em pacientes que frequentam os serviços.
\end{abstract}

Palavras-chave: HIV; AIDS; Supressão viral sustentada; Terapia antirretroviral de alta atividade; Coinfecção.

\begin{abstract}
Objective: to verify adherence to antiretroviral treatment and viral suppression, according to demographic, clinical and laboratory variables in patients seen at the HIV/AIDS outpatient clinic of HC-Unicamp in 2016. Method: crosssectional study on the demographic, epidemiological and clinical profile of patients treated at the Outpatient Clinic of Infectious Diseases at Hospital Dia of the State University of Campinas Hospital de Clínicas to assess adherence to ART and any adverse events recorded in 2016. Results: of the 339 medical records sampled from PLWHA, 278 $(82.0 \%)$ with regular use of antiretrovirals and $293(86.4 \%)$ with undetectable viral load (<40 copies / mL). The multiple logistic models, age, clinical complications, and side effects of medications are associated with lower adherence to ART. Viral suppression was more significant among men, with older age and shorter diagnosis time, and less frequent in patients with clinical complications and adverse effects of the medication. Conclusion: a greater integration between services can facilitate the rescue of PLWHA without clinical follow-up. The clinical management
\end{abstract}


of complications and adverse drug events are relevant to treatment adherence and viral suppression in patients attending the services.

Keywords: HIV; AIDS; Sustained virologic response; Antiretroviral therapy; highly active; Coinfection.

\begin{abstract}
Resumen
Objetivo: verificar la adherencia al tratamiento antirretroviral y la supresión viral, según variables demográficas, clínicas y de laboratorio en pacientes atendidos en la consulta externa de VIH / SIDA HC-Unicamp en 2016. Método: estudio transversal sobre el perfil demográfico, epidemiológico y clínico de los pacientes atendidos en el Ambulatorio de Enfermedades Infecciosas del Hospital Dia de la Universidad Estatal de Campinas para evaluar la adherencia al TAR y los eventos adversos registrados en 2016. Resultados: De las 339 historias clínicas de PVVS muestreadas, 278 $(82,0 \%)$ con uso regular de medicamentos antirretrovirales y $293(86,4 \%)$ con carga viral indetectable (<40 copias / $\mathrm{mL}$ ). En el modelo de logística múltiple, la edad, las complicaciones clínicas y los efectos secundarios de los medicamentos se asociaron con una menor adherencia al TAR. La supresión viral fue mayor entre los hombres, mayores y menos tiempo desde el diagnóstico; y menos frecuente en pacientes con complicaciones clínicas y efectos adversos de los medicamentos. Conclusión: Una mayor integración entre servicios puede facilitar el rescate de PVVS sin seguimiento clínico. El manejo clínico de las complicaciones y eventos adversos por medicamentos es relevante para la adherencia al tratamiento y la supresión viral en los pacientes que acuden a los servicios.

Palabras clave: VIH; Síndrome de inmunodeficiencia adquirida; Respuesta virológica sostenida; Terapia antirretroviral altamente activa; Coinfección.
\end{abstract}

\title{
1. Introdução
}

A utilização da Terapia Antirretroviral (TARV) teve grande impacto na diminuição da morbidade e mortalidade das pessoas vivendo com HIV/aids (PVHA), melhorando a qualidade e a expectativa de vida (Guibu, Barros, Donalisio, Tayra \& Alves, 2011; Ministério da Saúde, 2018), além de compor a estratégia de prevenção combinada adotada pelo Ministério da Saúde brasileiro para reduzir a transmissão sexual do vírus (Ministério da Saúde, 2017a).

Desde 2013, as metas estabelecidas pelo Conselho de Coordenação da UNAIDS (Joint United Nations Programme on HIV/AIDS) estabelecem alcançar até 2020 que 90\% de todas PVHA conheçam seu estado de HIV+, 90\% de todas as pessoas com diagnóstico de infecção pelo HIV recebam terapia antirretroviral e 90\% destas tenham supressão viral (UNAIDS, 2014). Embora o número de novas infecções esteja diminuindo no mundo na última década, esta queda ainda é lenta, particularmente após o início da pandemia da doença respiratória causada pelo vírus SARS-COV-2 (COVID-19) em 2020 que acarretou certa lentificação em outras ações de saúde pública (UNAIDS, 2020).

No Brasil, apesar da disponibilização da TARV, vários fatores podem dificultar o controle da infecção, entre eles o seguimento clínico insuficiente, a falta de adesão ao tratamento devido aos efeitos adversos de medicações, o tratamento prolongado, condições socioeconômicas precárias, entre outras (Ministério da Saúde, 2017b).

$\mathrm{O}$ acompanhamento clínico e a adesão à TARV são indicadores relevantes da qualidade da atenção e permitem monitorar o controle da infecção no indivíduo e indiretamente a transmissão na comunidade. Além disso, a não adesão do paciente ao protocolo clínico/medicamentoso pode indicar dificuldades da equipe de saúde na comunicação com o paciente e a falta de participação de outros setores de apoio ao cuidado multiprofissional.

O presente estudo tem como objetivo verificar a adesão ao tratamento antirretroviral, bem como o registro de carga viral indetectável como marcadores de controle da infecção e do seguimento clínico dos pacientes, segundo o perfil clínico, epidemiológico das PVHA e eventos adversos em pacientes do ambulatório de HIV/AIDS do HC-Unicamp.

\section{Metodologia}

Estudo transversal sobre o perfil demográfico, epidemiológico e clínico dos pacientes atendidos no Ambulatório de Infectologia no Hospital Dia da Universidade Estadual de Campinas para avaliar a adesão à TARV e eventuais eventos adversos registrados no ano de 2016.

Foi analisada amostra de prontuários de pacientes com HIV/aids atendidos no Hospital de Clínicas da Unicamp (HC- 
Unicamp) no ano de 2016, que em 2015 foi ao redor de 5000 pacientes. O tamanho amostral foi calculado para uma proporção de 0,4, erro admitido 5\% e nível de Confiança 95\%, resultando em 344 prontuários necessários (Morettin, 2010).

Utilizou-se como critérios de inclusão: idade superior ou igual a 18 anos, diagnóstico de infecção por HIV/aids pelo menos há 6 meses, (Classificação Internacional de Doenças - X revisão: CID-10 B-20 a B-24), ter registro de pelo menos um atendimento clínico em prontuário no ano de 2016 após o diagnóstico. Como critério de exclusão estabeleceu-se a presença de registro por qualquer outra condição clínica que não o seguimento da infecção por HIV e aids e a falta de confirmação diagnóstica.

Os dados foram coletados por meio de instrumento estruturado criado pelos autores (validado pelos mesmos e readequado após ajustes) que resultou no levantamento de variáveis sociodemográficas: sexo, idade classificada em faixas etárias (<30, 30 a 39, 40 a 49, 50 a 59 e $\geq 60$ ), escolaridade em anos $(<4,4$ a $8,>8$ e sem informação), procedência (Campinas, Região Metropolitana de Campinas, outros municípios e sem informação); epidemiológicos: categoria de exposição (sexual, parenteral, vertical e sem informação), orientação sexual (não-heterossexual, heterossexual, sem informação), tabagismo, uso de álcool, de drogas (não, sim e sem informação - considerando o registro afirmativo de uso de maconha, cocaína, crack, drogas injetáveis e/ou ecstasy); e clínicos-laboratoriais: registro de pelo menos uma infecção sexualmente transmissível (não, sim e sem informação - considerando gonorreia, sífilis, linfogranuloma venéreo, donovanose, cancro mole, herpes genital, hepatite B e C, condiloma acuminado), depressão, comorbidades (não, sim e sem informação considerando hipertensão arterial, diabetes mellitus e dislipidemia), intercorrências registradas em prontuário nos últimos 12 meses com Classificação Internacional de Doenças - CID diferente de B-20 a B-24 (não, sim e sem informação), último resultados de contagem de linfócitos CD4 em células $/ \mathrm{mm}^{3}$ ( $<200,200$ a 350, 351 a 500, $>500$ e sem informação), carga viral (indetectável, ou seja < 40 cópias por $\mathrm{ml}$, detectável e sem informação) e eventos adversos pelo uso de antirretrovirais registrado no prontuário.

Os desfechos estudados foram: carga viral indetectável e uso regular de TARV. Considerou-se uso regular os indivíduos que retiraram medicamentos antirretrovirais prescritos nos últimos 6 meses. Após análise bivariada dos desfechos segundo covariáveis de interesse, foram ajustados dois modelos múltiplos logísticos, incluindo-se as variáveis que apresentaram $\mathrm{p}<0,25$ no modelo univariado. As variáveis que restaram nos modelos finais foram as que obtiveram valor $\mathrm{p} \leq$ 0,05 .

A tabulação foi realizada pelo programa Microsoft Excel para Windows e expressos em frequências relativas e absolutas. O software estatístico SPSS 21.0 foi utilizado para as análises estatísticas.

O projeto do estudo foi aprovado pelo Comitê de Ética em Pesquisa da Universidade Estadual de Campinas (Unicamp) - Parecer n ${ }^{\circ} 1.698 .265$.

\section{Resultados}

Foram analisados 339 prontuários de PVHA em seguimento clínico-ambulatorial, entre os quais 278 (82\%) com uso regular de antirretrovirais e 293 (86,4\%) com carga viral indetectável (Tabelas 1 e 2). A maioria dos prontuários examinados era de indivíduos do sexo masculino 210 (61,9\%), com idade entre 40 e 49 anos (34,2\%), procedente da região metropolitana de Campinas (81,7\%). A principal forma de infecção viral foi referida na categoria de exposição sexual em 246 pacientes (72,6\%), sendo que, $173(51,0 \%)$ se declararam heterossexual (Tabela 1). Os pacientes investigados apresentaram grande percentual de comorbidades $(47,8 \%)$ e de intercorrências clínicas nos últimos 12 meses relacionadas a qualquer CID que não o B20 a B24 (65,8\%), com 12,9\% apresentando contagem de células CD4 < $350 / \mathrm{mm} 3$ no último registro do ano. Os eventos adversos ao uso dos antirretrovirais foram identificados nos prontuários de 76 (22,4\%), sendo os principais: náuseas, sonolência, farmacodermia, diarreia, tontura e alterações neurológicas. 
Tabela 1 - Distribuição percentual de variáveis sociodemográficas e epidemiológicas em PVHA em seguimento no Hospital de Clínicas da Unicamp, Campinas, São Paulo, Brasil, 2016.

\begin{tabular}{|c|c|c|}
\hline Variáveis & & Freq. (\%) \\
\hline & Feminino & $129(38,1)$ \\
\hline Sexo & Masculino & $210(61,9)$ \\
\hline \multirow[t]{5}{*}{ Faixa Etária (anos) } & $<30$ & $45(13,3)$ \\
\hline & 30 a 39 & $76(22,4)$ \\
\hline & 40 a 49 & $116(34,2)$ \\
\hline & 50 a 59 & $79(23,3)$ \\
\hline & $\geq 60$ & $23(6,8)$ \\
\hline \multirow{4}{*}{ Escolaridade (anos) } & $<4$ & $16(4,7)$ \\
\hline & 4 a 8 & $37(10,9)$ \\
\hline & $>8$ & $64(18,9)$ \\
\hline & Sem informação & $222(65,5)$ \\
\hline \multirow{4}{*}{ Procedência } & Campinas & $127(37,5)$ \\
\hline & $\mathrm{RMC} * *$ & $150(44,2)$ \\
\hline & Outros municípios & $59(17,4)$ \\
\hline & Sem informação & $3(0,9)$ \\
\hline \multirow{4}{*}{$\begin{array}{l}\text { Categoria de } \\
\text { exposição }\end{array}$} & Sexual & $246(72,6)$ \\
\hline & Parenteral & $24(7,1)$ \\
\hline & Vertical & $5(1,5)$ \\
\hline & Sem informação & $64(18,8)$ \\
\hline \multirow{3}{*}{ Orientação sexual } & Não-Heterossexual & $81(23,9)$ \\
\hline & Heterossexual & $173(51,0)$ \\
\hline & Sem informação & $85(25,1)$ \\
\hline \multirow{3}{*}{ Tabagismo } & Não & $191(56,3)$ \\
\hline & Sim & $135(39,9)$ \\
\hline & Sem informação & $13(3,8)$ \\
\hline \multirow{3}{*}{ Uso de álcool } & Não & $247(72,9)$ \\
\hline & Sim & $78(23,0)$ \\
\hline & Sem informação & $14(4,1)$ \\
\hline \multirow{3}{*}{ Uso de droga } & Não & $189(55,7)$ \\
\hline & Sim & $63(18,6)$ \\
\hline & Sem informação & $87(25,7)$ \\
\hline Total & & $339(100,0)$ \\
\hline
\end{tabular}

Fonte: Autores. 
Tabela 2 - Distribuição percentual de variáveis clínico-laboratoriais em PVHA em seguimento no Hospital de Clínicas da Unicamp, Campinas, São Paulo, Brasil, 2016.

\begin{tabular}{|c|c|c|}
\hline Variáveis & & Freq. (\%) \\
\hline \multirow{3}{*}{ Comorbidades } & Não & $162(47,8)$ \\
\hline & Sim & $176(51,9)$ \\
\hline & Sem informação & $1(0,3)$ \\
\hline \multirow{3}{*}{$\begin{array}{l}\text { Infecção Sexualmente } \\
\text { Transmissível }\end{array}$} & Não & $175(51,6)$ \\
\hline & Sim & $106(31,3)$ \\
\hline & Sem informação & $58(17,1)$ \\
\hline \multirow{3}{*}{ Depressão } & Não & $165(48,7)$ \\
\hline & Sim & $73(21,5)$ \\
\hline & Sem informação & $101(29,8)$ \\
\hline \multirow{3}{*}{$\begin{array}{l}\text { Intercorrências nos últimos } \\
12 \text { meses }\end{array}$} & Não & $114(33,6)$ \\
\hline & $\operatorname{Sim}$ & $223(65,8)$ \\
\hline & Sem informação & $2(0,6)$ \\
\hline \multirow{5}{*}{$\begin{array}{l}\text { Último CD4 em } \\
\text { células } / \mathrm{mm}^{3}\end{array}$} & $<200$ & $14(4,1)$ \\
\hline & 200 a 350 & $30(8,8)$ \\
\hline & 350 a 500 & $53(15,6)$ \\
\hline & $>500$ & $239(70,6)$ \\
\hline & Sem informação & $3(0,9)$ \\
\hline \multirow{3}{*}{ Carga viral } & Indetectável & $293(86,4)$ \\
\hline & Detectável & $44(13,0)$ \\
\hline & Sem informação & $2(0,6)$ \\
\hline \multirow{2}{*}{ Uso regular de TARV } & Não & $61(18,0)$ \\
\hline & Sim & $278(82,0)$ \\
\hline \multirow{2}{*}{$\begin{array}{l}\text { Eventos adversos à } \\
\text { medicação }\end{array}$} & Não & $263(77,6)$ \\
\hline & Sim & $76(22,4)$ \\
\hline Total & & $339(100,0)$ \\
\hline
\end{tabular}

Fonte: Autores.

Os resultados do último exame de contagem de linfócitos T-CD4+ variaram de no mínimo de 4 e máximo de 2.429 células, resultando em uma média de 693 células $/ \mathrm{mm}^{3}$ (desvio padrão = 401,7). Foram 239 (70,5\%) PVHA com dosagens acima de 500 células $/ \mathrm{mm}^{3}$, A carga viral indetectável contagem abaixo de 40 cópias /mL foi registrada em 293 (86,4\%) prontuários, sendo que os resultados restantes variaram de 57 a 62.234 cópias/mL, com média de 313,5 cópias/mL (desvio padrão $=14.659)$.

No modelo múltiplo, o uso regular de TARV foi maior entre os homens, com maior idade e com menor tempo do diagnóstico. Como é de se esperar, a maior adesão ocorreu entre os com carga viral não detectável nos últimos 12 meses, sem intercorrências clínicas (Tabela 3). 
Tabela 3 - Variáveis associadas ao uso regular de antirretroviral em modelo de regressão logística múltipla em pacientes que compareceram ao serviço HIV/aids do Hospital de Clínicas da Unicamp, São Paulo, Brasil, 2016.

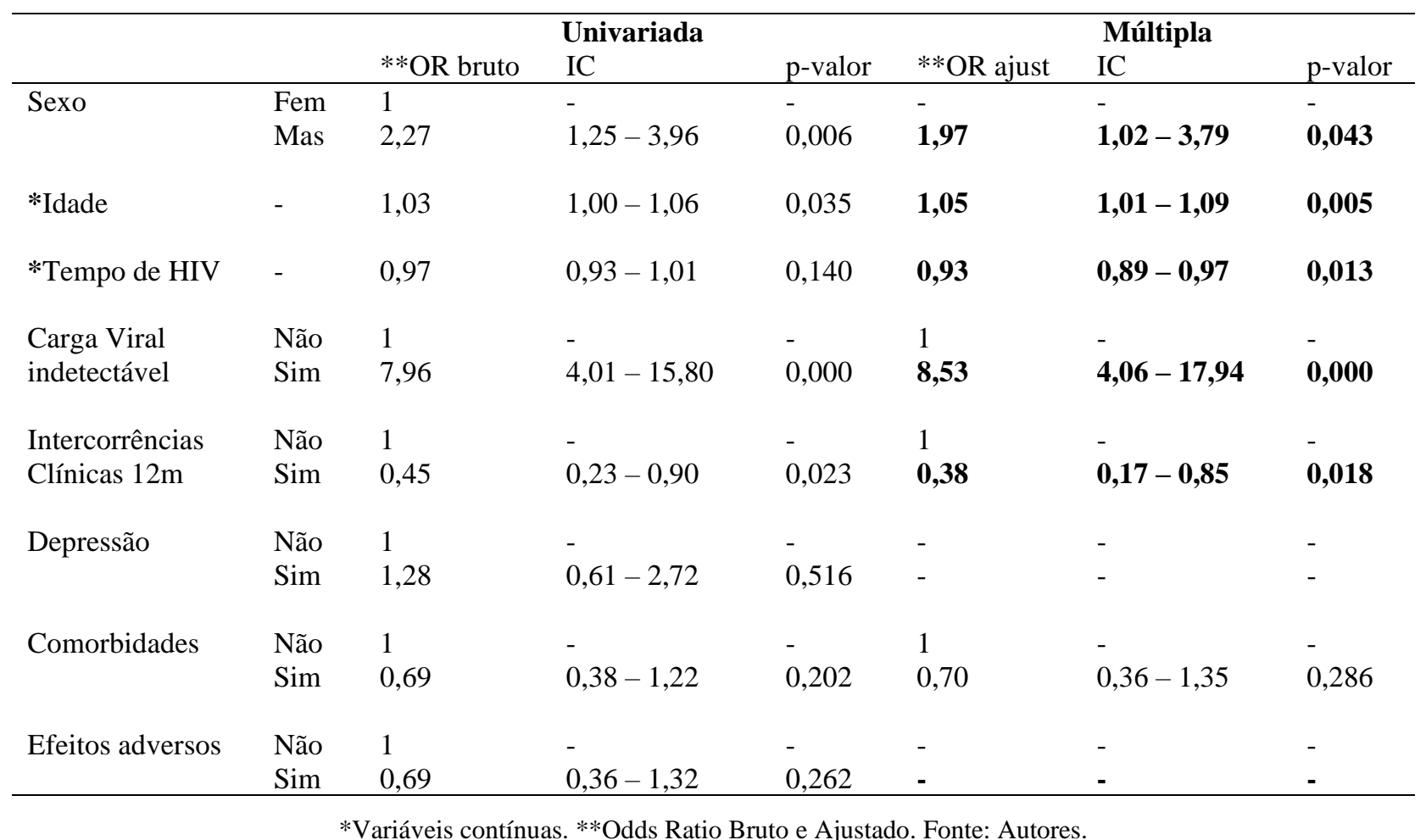

A Tabela 4 mostra as variáveis associadas à carga viral indetectável (< 40 cópias por ml) na última consulta no prontuário. Em análise de regressão logística múltipla, observou-se que se associaram positivamente à carga viral indetectável o uso de TARV, ausência de intercorrências clínicas e ausência de eventos adversos notificados nos prontuários (Tabela 4). 
Tabela 4 - Variáveis associadas à carga viral de HIV indetectável (<40 copias/mL) em modelo de regressão logística múltipla em pacientes que compareceram ao serviço HIV/aids do HC-Unicamp em 2016.

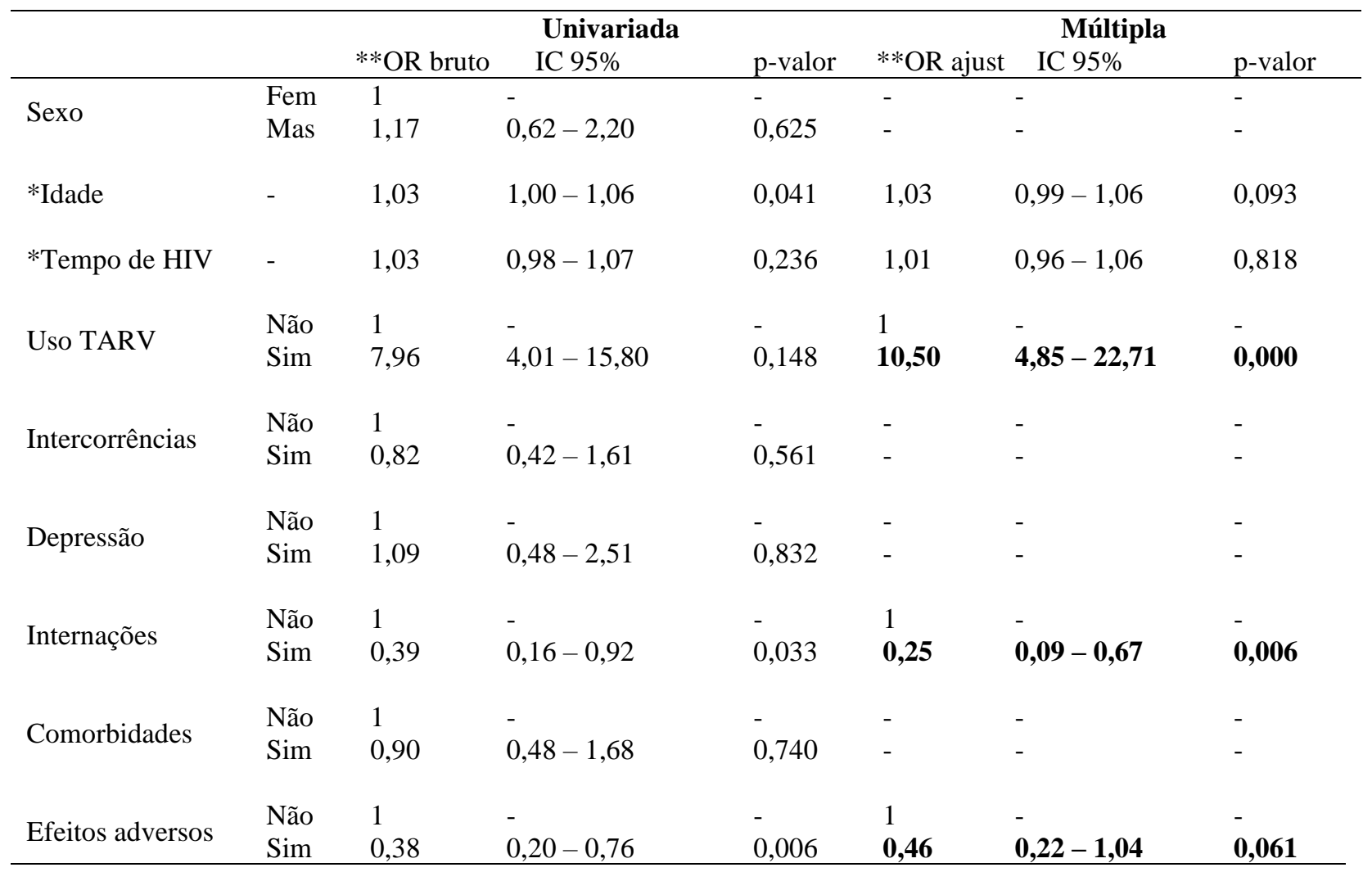

*Variáveis contínuas. **Odds Ratio Bruto e Ajustado. Fonte: Autores.

Entre as coinfecções relacionadas ao HIV/aids anotadas nos prontuários destacam-se: herpes zoster, tuberculose, monilíase inguinal ou esofágica, neurotoxoplasmose, hepatite $\mathrm{C}$, pneumocistose e sífilis (Tabela 5). 
Tabela 5 - Distribuição das principais coinfecções da amostra de PVHA em seguimento no Hospital de Clínicas da Unicamp, Campinas, SP, 2016.

\begin{tabular}{lll}
\hline Coinfecção & $\mathbf{N}$ & \% \\
\hline Herpes Zoster & 37 & 10,9 \\
Tuberculose & 32 & 9,4 \\
Monilíase inguinal ou esofágica & 26 & 7,7 \\
Neurotoxoplasmose & 14 & 4,1 \\
Hepatite C & 13 & 3,8 \\
Pneumocistose & 13 & 3,8 \\
Sífilis & 12 & 3,5 \\
Hepatite A & 11 & 3,2 \\
Pneumonia & 9 & 2,7 \\
Cripotosporidíase & 8 & 2,4 \\
Herpes labial ou genital & 6 & 1,8 \\
Neurossífilis & 4 & 1,2 \\
Neurocriptococose & 4 & 1,2 \\
Hepatite B & 2 & 0,6 \\
Sarcoma de Kaposi & 2 & 0,6 \\
Toxoplasmose ocular & 2 & 0,6 \\
Mononucleose & 1 & 0,3 \\
\hline
\end{tabular}

Fonte: Autores.

\section{Discussão}

O perfil dos pacientes com infecção HIV/aids em seguimento clínico em 2016 no HC-Unicamp revela indivíduos de todas as idades, escolaridades, procedentes principalmente de Campinas e região metropolitana, com referência de transmissão sexual, com baixo registro de uso de álcool, tabaco e drogas. As altas prevalências de comorbidades (51,9\%) e de intercorrências clínicas nos últimos 12 meses (65,8\%) expõem o papel do HC-Unicamp como referência da região para atendimento HIV/aids, recebendo com frequência, casos de maior complexidade. O registro de depressão em $21,5 \%$ dos casos, chama a atenção.

Observou-se percentual de adesão ao tratamento antirretroviral de $82 \%$ entre os pacientes que compareceram no ano de 2016, próximo à meta de 90\% de tratamento entre as PVHA. Esse percentual de adesão não representa a totalidade dos pacientes registrados no serviço, e tampouco a totalidade das PVHA da região pois trata-se dos que compareceram no período de estudo. Entretanto é um indicador a ser monitorado, particularmente nos serviços de referência, com perspectivas de identificar os abandonos e as adesões incompletas. A maior integração entre os serviços de prevenção e assistência às PVHA na região poderia apresentar um painel mais realista do real percentual de indivíduos sem seguimento clínico e auxiliar no seu resgate.

A carga viral indetectável em 92,5\% e a última dosagem de linfócitos T-CD4 >350 cel/ $/ \mathrm{mm}^{3}$ em $85,6 \%$ dos pacientes reafirmam o impacto do seguimento clínico regular e do uso contínuo da medicação (Silva, Duarte \& Lima, 2020). A meta UNAIDS de $90 \%$ de supressão viral entre os pacientes em tratamento foi superada nesta casuística, embora não tenham sido analisados pacientes em abandono de tratamento ou que não compareceram ao serviço no ano de 2016. O Brasil atingiu a meta de $90 \%$ de pessoas tratadas com supressão viral em 2019, apesar da ainda baixa cobertura de ações de prevenção em populações chave (homens que fazem sexo com homens, pessoas "trans", pessoas que usam álcool e outras drogas, pessoas privadas de liberdade e trabalhadores sexuais) (UNAIDS, 2020; Jalil et al., 2017). 
Dados nacionais apontam tendência de aumento do número de pessoas diagnosticadas com HIV, particularmente após a ampliação das indicações de TARV e tratamento precoce (Jalil et al., 2017). Dados da UNAIDS de 2019 registram que o Brasil se aproximou das metas $(90,90,90)$ na última década ao apresentar $88 \%$ pessoas vivendo com HIV/aids que sabe seu status, 78\% destas estão em tratamento e 94\% de supressão viral entre os tratados (UNAIDS, 2020).

No estado de São Paulo, estudo verificou os benefícios imediatos resultantes do seguimento clínico e inserção/reinserção de usuários no tratamento e intensificação da adesão, ofertados nos serviços especializados de HIV e aids. Associado a intervenções de educação em saúde com a participação dos profissionais das equipes multiprofissionais, verificouse um aumento dos marcadores específicos da meta 90-90-90 (Ministério da Saúde, 2019).

A má adesão a TARV foi maior entre homens, mais jovens, com menor tempo de diagnóstico de HIV antirretrovirais, sem intercorrências clínicas nos últimos 12 meses e sem registro de eventos adversos à medicação. Intercorrências clínicas, incluindo internações no último ano são oportunidades de estreitar a adesão à TARV de pacientes possivelmente com quadros mais graves.

Como era de se esperar a supressão viral e as dosagens de linfócitos TCD4+ maiores que $350 / \mathrm{mm}^{3}$ estavam presentes em maior frequência entre os pacientes aderentes à TARV e que compareceram no período de estudo. Estes resultados reafirmam neste serviço a importância de se restabelecer o vínculo dos pacientes ao seguimento clínico ambulatorial.

Considerada uma das causas mais frequentes de falha virológica, as causas de baixa adesão ao tratamento são variadas e incluem esquemas terapêuticos complexos (diferentes drogas, quantidade de doses), esquecimento, abuso de álcool e outras substâncias psicoativas, transtornos psiquiátricos, baixa escolaridade, relação médico-paciente precária, dificuldade de acesso aos serviços de saúde, efeitos adversos da medicação, dentre outros (Ministério da Saúde, 2018).

Chama a atenção a prevalência de 21,5\% de depressão registrada nos prontuários. Quadros depressivos são pouco diagnosticados e não tratados adequadamente, não só em PVHA. Além do impacto na qualidade de vida e saúde das PVHA, a depressão é condição que propicia, por si só, dificuldades no uso regular da medicação (Loch et al., 2020). Entre as dificuldades que a doença impõe sobre o indivíduo diariamente, destaca-se também a consciência da constante necessidade de se evitar a transmissão ao manter ou iniciar novos relacionamentos afetivos. Estudos mostram que a depressão pode ser responsável pela diminuição da contagem de células TCD4+ e aumento da carga viral, acelerando a progressão da doença (Horberg et al., 2008; Remor, Penedo, Shen \& Schneiderman, 2007).

No amplo espectro de engajamento das PVHA aos serviços, o atendimento multidisciplinar focando individualmente os casos, o suporte à saúde mental e à assistência social têm sido ressaltados por vários autores (Camargo et al, 2019). Destacase, a importância do cuidado integral e multiprofissional das-PVHA; a fim de que a abordagem dos aspectos biopsicossociais e uma visão de tratamento integral, centradas nas necessidades individuais propiciem impacto na adesão ao tratamento e, consequentemente, no prognóstico desses pacientes. Uma vez identificadas as potencialidades e dificuldades das equipes, a educação permanente pode fortalecer o acolhimento, a clínica ampliada e o trabalho em equipe, a fim de acessar várias dimensões do cuidado à PVHA, considerando a organização dos serviços e aspectos dos determinantes sociais em saúde (Camargo et al, 2019; Gardner, McLees, Steiner, Del Rio \& Burman, 2011).

Cerca de $16,4 \%$ dos pacientes podem não aderir ao tratamento devido aos efeitos adversos da TARV, devendo esse assunto ser abordado preferencialmente em todas as consultas, sobretudo com aqueles pacientes em falha virológica (Knoll, Maeyama, Schmidlin \& Branchi, 2019; Detsis et al., 2017). O ajuste oportuno de esquemas terapêuticos e o acesso à medicação são fatores relevantes no controle da infecção, associadas à adesão ao tratamento e à supressão viral, como sugerido pelos resultados do presente estudo.

A associação entre a carga viral indetectável, o uso e o tempo de uso de TARV têm sido evidentes desde a implantação dos protocolos de assistência aos pacientes (Ministério da Saúde, 2018, 2019). Entretanto, ressalta-se o registro de 
eventos adversos como preditor de falhas no controle da infecção associada ao aumento da carga viral. Além dos eventos adversos descritos neste estudo (vômitos, diarreia e farmacodermias), reações adversas fisicamente visíveis, tais como lipodistrofias, escurecimento da pele, perda de cabelos, ganho ou perda de peso estão associados a um risco maior de revelação/suspeição não intencional da situação sorológica do paciente, causando baixa autoestima, estigmatização e, consequentemente, reduzindo a adesão desses pacientes ao tratamento (Detsis et al., 2017).

O perfil de coinfecções e de doenças oportunistas encontrado revela o desafio do controle clínico dos pacientes e do acompanhamento longitudinal e multiprofissional. Destaca-se a coinfecção tuberculose e HIV/Aids, em 9,4\% dos casos. Considerando-se que o indivíduo infectado pelo HIV tem risco de adoecimento pelo Mycobacterium tuberculosis maior que a população, a instituição de terapia antirretroviral tão logo o indivíduo HIV positivo preencha os critérios é um recurso importante, pois o HIV é sabidamente o mais potente fator ativador de tuberculose até hoje conhecido (Abdulrahman, Ganasegeran, Rampal \& Martins, 2019; Melo, Donalisio \& Cordeiro, 2017).

Assim, a organização da assistência em saúde contribui para o diagnóstico precoce e controle da infecção por HIV e coinfecções, à medida que as unidades de atendimento na atenção primária, nos níveis secundário e terciário estejam integrados para possibilitar a assistência precoce encaminhar às PVHA em seguimento irregular.

Como limitações deste estudo, podemos citar: o mal preenchimento ou errôneo dos prontuários, alguns pacientes possuíam volumes documentais de prontuários muito extensos e a ausência de exames diagnósticos para HIV e aids. Todos esses vieses foram controlados com a randomização da seleção dos prontuários.

\section{Conclusão}

Concluindo, o tempo do diagnóstico, bem como o uso de TARV refletem a adesão ao tratamento e associam-se à supressão viral, mostrando a importância do vínculo dos pacientes com o serviço. O manejo dos efeitos colaterais das drogas prescritas pode ter importante impacto nos indicadores de recomposição imunológica e adesão ao tratamento.

Mesmo em serviços de referência de pacientes com quadros mais graves e complexos, as metas UNAIDS podem ser alcançadas. Entretanto atenção deve ser voltada para os que não comparecem aos serviços, a partir de uma maior integração entre os serviços de assistência e prevenção às PVHA. Além disso, para a adesão ao tratamento e seguimento clínico, contribuem o acesso aos medicamentos, apoio de atendimento multiprofissional, retaguarda da atenção à saúde mental, além das atividades de educação em saúde e apoio social aos pacientes em vulnerabilidade.

\section{Agradecimentos}

Este estudo recebeu apoio da Coordenação de Aperfeiçoamento de Pessoal de Nível Superior (CAPES) / Ministério da Educação: Código de Financiamento 001.

\section{Referências}

Abdulrahman, S. A., Ganasegeran, K., Rampal, L. \& Martins, O. F. (2019). HIV Treatment Adherence - A Shared Burden for Patients, Health-Care Providers, and Other Stakeholders. AIDS Reviews, 21(1), 28-39. https://pubmed.ncbi.nlm.nih.gov/30899114/

Camargo, C. C., Cavassan, N. R. V., Tasca, K. I., Meneguin, S., Miot, H. A. \& Souza, L. R. (2019). Depression and Coping Are Associated with Failure of Adherence to Antiretroviral Therapy Among People Living with HIV/AIDS. AIDS Research and Human Retroviruses, 35(11-12), 1181-1189. https://pubmed.ncbi.nlm.nih.gov/31592722/

Detsis, M., Tsioutis, C., Karageorgos, S. A., Sideroglou, T., Hatzakis, A. \& Mylonakis, E. (2017). Factors Associated with HIV Testing and HIV Treatment Adherence: A Systematic Review. Current Pharmaceutical Design, 23(18), 2568-2578. https://pubmed.ncbi.nlm.nih.gov/28356038/

Gardner, E. M., McLees, M. P., Steiner, J. F., Del Rio, C., \& Burman, W. J. (2011). The spectrum of engagement in HIV care and its relevance to test-andtreat strategies for prevention of HIV infection. Clinical Infectious Diseases, 52(6), 793-800. https://pubmed.ncbi.nlm.nih.gov/21367734/ 
Guibu, I. A., Barros, M. B., Donalisio, M. R., Tayra, A. \& Alves, M. C. (2011). Survival of AIDS patients in the Southeast and South of Brazil: analysis of the 1998-1999 cohort. Cadernos de Saúde Pública, 27(Suppl), 1:S79-92. https://www.scielo.br/j/csp/a/hcyPQmmqZ6bQbRdWpFLGqJN/?lang=en

Horberg, M. A., Silverberg, M. J., Hurley, L. B., Towner, W. J., Klein, D. B., Bersoff-Matcha, S., Weinberg, W. G., Antoniskis, D., Mogyoros, M., Dodge, W. T., Dobrinich, R., Quesenberry, C. P. \& Kovach, D. A. (2008). Effects of depression and selective serotonin reuptake inhibitor use on adherence to highly active antiretroviral therapy and on clinical outcomes in HIV-infected patients. Journal of Acquired Immune Deficiency Syndromes, 47, 384-90. https://pubmed.ncbi.nlm.nih.gov/18091609/

Jalil, E. M., Wilson, E. C., Luz, P. M., Velasque, L., Moreira, R. I., Castro, C. V., Monteiro, L., Garcia, A. C., Cardoso, S. W., Coelho, L., McFarland, W., Liu, A. y., Veloso, V. G., Buchbinder, S. \& Grinsztejn, B. (2017). HIV testing and the care continuum among transgender women: population estimates from Rio de Janeiro, Brazil. Journal of the International AIDS Society, 20, 21873. https://www.ncbi.nlm.nih.gov/pmc/articles/PMC5640309/

Knoll, R. K., Maeyama, M. A., Schmidlin, P. C. \& Branchi, T. L. (2019). Práticas de uma equipe multiprofissional para pessoas vivendo com hiv/aids: um estudo de caso em um município da Foz do Rio Itajaí-açu, Santa Catarina-Brasil. Arquivos Catarinenses de Medicina, 48(4), 02-15. http://www.acm.org.br/acm/seer/index.php/arquivos/article/view/381

Loch, A. P., Caraciolo, J. M. M., Rocha, S. Q., Fonsi, M., Souza, R. A., Gianna, M. C., Gonçalves, M. C. \& Kalichman, A. O. (2020). An intervention for the implementation of clinical monitoring in specialized care services to people living with HIV/AIDS. Cadernos de Saúde Pública, 36(5), e00136219. https://www.scielo.br/j/csp/a/6FMHztrWVQZ8wfWxnC9qn8s/abstract/?lang=en

Melo, M. C., Donalisio., M. R. \& Cordeiro, R. C. (2017). Sobrevida de pacientes com AIDS e coinfecção pelo bacilo da tuberculose nas regiões Sul e Sudeste do Brasil. Ciência \& Saúde Coletiva, 22(11), 3781-3792. https://doi.org/10.1590/1413-812320172211.26352015

Ministério da Saúde (2017a). Prevenção Combinada do HIV. Bases conceituais para profissionais, trabalhadores(as) e gestores(as) de saúde. p. 123. http://www.aids.gov.br/pt-br/pub/2017/prevencao-combinada-do-hiv-bases-conceituais-para-profissionais-trabalhadoresas-e-gestores

Ministério da Saúde (2017b). Nota Informativa No007/2017 - DDAHV/SVS/MS. http://www.aids.gov.br/pt-br/legislacao/nota-informativa-no-0072017-ddahvsvs-ms

Ministério da Saúde. (2018). Protocolo clínico e diretrizes terapêuticas para manejo da infecção pelo HIV em adultos. http://www.aids.gov.br/ptbr/pub/2013/protocolo-clinico-e-diretrizes-terapeuticas-para-manejo-da-infeccao-pelo-hiv-em-adultos

Ministério da Saúde. (2019). Relatório de monitoramento clínico do HIV. https://www.gov.br/saude/pt-br/centrais-de-conteudo/publicacoes/publicacoessvs/aids/relatorio_de_monitoramento_clinico_aids.pdf

Morettin, P. A. (2010). Estatística Básica. Saraiva.

Murray, J. F. (1991). Tuberculosis and human immunodeficiency virus infection during the 1990's. Bulletin of the International Union Against Tuberculosis and Lung Disease, 66(1), 21-25. https://pubmed.ncbi.nlm.nih.gov/1859939/

Remor, E., Penedo, F. J., Shen, B. J. \& Schneiderman, N. (2007). Perceived stress is associated with CD4+ cell decline in men and women living with HIV/AIDS in Spain. AIDS Care, 19(2), 215-9. https://pubmed.ncbi.nlm.nih.gov/17364401/

Silva, L.A.V., Duarte, F.M. \& Lima, M. (2020). Modelo matemático pra uma coisa que não é matemática: narrativas de médicos/as infectologistas sobre carga viral indetectável e intransmissibilidade do HIV. Physis: Revista de Saúde Coletiva, 30(01), e300105. https://doi.org/10.1590/S0103-73312020300105

UNAIDS (2014). 90-90-90: An ambitious treatment target to help end the AIDS epidemic. Joint United Nations Programme on HIV/AIDS. https://www.unaids.org/sites/default/files/media_asset/90-90-90_en.pdf

UNAIDS (2020). Joint United Nations Programme on HIV/AIDS Seizing the moment, tackling entrenched inequalities to end epidemics. https://www.aidsdatahub.org/resource/2020-global-aids-update-seizing-moment-tackling-entrenched-inequalities-end-epidemics. 